sicher gerne, dass ich Ergebnisse und nicht „results“ oder „findings" sage, denn die moderne Unart, englische Wörter in deutsche Sätze einzufügen, mag er gar nicht.

Der Mensch Draeger ist trotz dieses beruflichen Erfolgs ein bescheidener Mensch, lebt geradezu spartanisch, fährt normale Autos, allerdings immer mit dem stärkst möglichen Motor. Das gleiche gilt für Motorboote. Er ist ein guter Skiläufer und ausgezeichneter Pilot, der so gut wie alle Kongresse in Europa mit dem eigenen Flugzeug besucht. Immer an seiner Seite wie auch im Leben die Copilotin Frau Dr. Brigitte Draeger, mit der er seit 45 Jahren verheiratet ist. Von drei tüchtigen Kindern trat eine Tochter in die medizinischen Fußstapfen des Vaters - sie ist Ordinaria für Anatomie in Bern.

Vieles gäbe es noch lobend zu erwähnen, dass er herzlich und boshaft lachen kann, Spass versteht - so liebt er den so

\section{Dankesrede anlässlich der Verleihung der Ehrenmitgliedschaft der Österreichischen Ophthalmologischen Gesellschaft}

\author{
Verehrter Herr Präsident, \\ liebe Freunde und Kollegen in der Österreichischen Ophthal- \\ mologischen Gesellschaft!
}

Die heutige Verleihung der Ehrenmitgliedschaft der Österreichischen Ophthalmologischen Gesellschaft ist für mich eben nicht etwa eine Ehrung, wie sie einem (in diesem Alter) ab und an widerfährt - es ist dies für mich etwas ganz Besonderes, Außerordentliches, das mich zutiefst anrührt. Jörg Zehetbauer hat schon auf die sehr frühen Bindungen zu dieser ehrwürdigen Gesellschaft hingewiesen - in der Tat bedeutet dies aber persönlich für mich wirklich noch viel mehr: Seit dem Sommer 1938, als ich in die 3. Klasse der Volksschule zu Dornbach im 17. Bezirk eingeschult wurde, hat Wien, Österreich eine ganz andere Qualität für mich bekommen und immer behalten, als dies für alle anderen Orte gilt, in denen ich schon gelebt habe. Es ist mir wirklich zur Heimat geworden, hier, bei Ihnen fühle ich mich zu Haus. Insofern haben Sie mir alle eine ganz, ganz besondere Freude mit dieser ehrenvollen Entscheidung gemacht - ich danke allen Mitgliedern dieser, unserer Gesellschaft, Ihrem Vorstand, dem Herrn Präsidenten von ganzem Herzen!

Es hat mich diese frühe Bindung ja dann nie wieder losgelassen, den Augenspiegel-Kurs habe ich z. B. im Sommersemester 1953 an der Universitäts-Augenklinik in Innsbruck absolviert, schon in dieser Zeit, als Student, Freunde aus dem Kollegenkreis gewonnen, mit denen mich noch heute eine enge Freundschaft verbindet. (Davon abgesehen, treffe ich z. B. auch noch Dornbacher Klassenkameraden in jedem Jahr). „very british bathing pleasure" des Oxford ophthalm. Kongresses - und auch Spaß verteilt, so gelang es ihm einmal, ein biederes burgenländisches Ehepaar zu einer Wattwanderung zu überreden, weil dies ein einmaliges Erlebnis sei. Stellen Sie sich vor, im Schlick zu waten, manchmal bis zu den Hüften im Wasser und immer die Angst vor sich, die Flut könnte einmal früher kommen. Das hat Draeger Spass gemacht.

Weil auch eine persönlich gefärbte Laudatio einmal enden muss, darf ich nun im Namen des Vorstandes, der Mitglieder und in meinem Namen dem neuen Ehrenmitglied Prof. Dr. Draeger, dir lieber Jörg, Urkunde deiner Ehrenmitgliedschaft der österreichischen ophthalmologischen Gesellschaft feierlich geziemend überreichen.

Prim. Prof. Dr. Georg Zehetbauer
Der nächste Schritt war natürlich dann schon auf die Ophthalmologie bezogen: Auf der Jahrestagung, der ÖOG 1959 war ich bereits mit einem eigenen wissenschaftlichen Beitrag vertreten, einem Thema, das mir ganz besonders am Herzen lag, das mich bis heute nicht verlassen hat, der besonders präzisen, frühen Glaukom-Diagnostik, damals der binokularen Tonographie, die die von Friedenwald und Grant entwickelten Methoden physikalisch und physiologisch hinterfragte, zu verbessern suchte.

Seither habe ich nur wenige Tagungen unserer schönen Gesellschaft versäumt - jedes Mal, wenn ich dabei war, einen wissenschaftlichen Beitrag abgeliefert.

Neben diesen unvergesslichen Tagungen unserer Gesellschaft waren es darüber hinaus auch noch andere Anlässe, die mich nach Österreich zurück zogen: Zwei Mal hatte ich die hohe Ehre, als Referent vor der Wiener Ophthalmologischen Gesellschaft vorzutragen, habe dabei immer das Interesse, die freundschaftliche Resonanz auf das Dankbarste empfunden, diese beiden Besuche jeweils in besonders schöner Erinnerung behalten. Unvergesslich bleibt auch der 2. Kongress der Europäischen Ophthalmologischen Gesellschaft in Wien 1964 - wiederum vor allem wegen seiner so besonders warmen, herzlichen, freundschaftlichen Atmosphäre. Diese nun wiederum ist natürlich das Verdienst der jeweils verantwortlichen, mitwirkenden Kollegen - so habe ich mich Verehrung und Bewunderung zu Prof. Boeck, Prof. Hruby, Prof. Hofmann und vielen anderen Lehrern und Freunden aufgeschaut.

Aus allen diesen Gründen ist es mir nun in der Tat eben eine ganz besondere Ehre, von Ihnen so freundlich ausgezeichnet worden zu sein - ich werde mich bemühen, diesem Anspruch Rechnung zu tragen, weiterhin ein treues Mitglied unserer schönen Gesellschaft zu sein.

Ich danke Ihnen sehr! 